\title{
Gram stain to the rescue: a case report of cerebral phaeohyphomycosis by Cladophialophora bantiana in an immunocompetent 24-year-old
}

Perceus Mody ${ }^{1 *}$ (D), Paul Wada², Karen C. Bloch², Michail S. Lionakis ${ }^{3,4}$, Katie D. White ${ }^{2}$, Alexander S. Maris ${ }^{1}$, Tonya Snyder ${ }^{1}$, Jennifer Steinhauer ${ }^{1}$ and Romney Humphries ${ }^{1}$

\begin{abstract}
Background: Fungal brain abscesses in immunocompetent patients are exceedingly rare. Cladophialophora bantiana is the most common cause of cerebral phaeohyphomycosis, a dematiaceous mold. Radiological presentation can mimic other disease states, with diagnosis through surgical aspiration and growth of melanized fungi in culture. Exposure is often unknown, with delayed presentation and diagnosis.

Case presentation: We present a case of cerebral phaeohyphomycosis in a 24-year-old with no underlying conditions or risk factors for disease. He developed upper respiratory symptoms, fevers, and headaches over the course of 2 months. On admission, he underwent brain MRI which demonstrated three parietotemporal rim-enhancing lesions. Stereotactic aspiration revealed a dematiaceous mold on staining and the patient was treated with liposomal amphotericin B, 5-flucytosine, and posaconazole prior to culture confirmation. He ultimately required surgical excision of the brain abscesses and prolonged course of antifungal therapy, with clinical improvement.

Conclusions: Culture remains the gold standard for diagnosis of infection. Distinct microbiologic findings can aid in identification and guide antimicrobial therapy. While little guidance exists on treatment, patients have had favorable outcomes with surgery and combination antifungal therapy. In improving awareness, clinicians may accurately diagnose disease and initiate appropriate therapy in a more timely manner.
\end{abstract}

Keywords: Cladophialophora bantiana, Brain abscess, Dematiaceous mold, Melanized fungi, Cerebral phaeohyphomycosis, Case report

\section{Background}

Primary cerebral phaeohyphomycosis is a rare infection caused by brown-black pigmented fungi, namely dematiaceous (melanized) molds [1]. It was first described in 1974 as tissue invasion by pigmented septate hyphae [2].

\footnotetext{
*Correspondence: perceus.mody@vumc.org

${ }^{1}$ Department of Pathology, Immunology and Microbiology, Vanderbilt University Medical Center, 1301 Medical Center Dr., TVC 4524, Nashville, TN 37232, USA

Full list of author information is available at the end of the article
}

Of note, more than 150 species and 70 genera have been implicated in a variety of human diseases [3]. They are rarely involved in central nervous system (CNS) infections, however they have a proclivity for immunocompetent hosts and those with inherited CARD9 deficiency [4, 5]. The most commonly cultured melanized fungi include Cladophialophora, Rhinocladiella, Curvularia, Verruconis, Exophiala, Veronaea and Fonsecaea [6-10]. In a retrospective review of 101 cases of primary CNS phaeohyphomycosis, Cladophialophora bantiana was by far

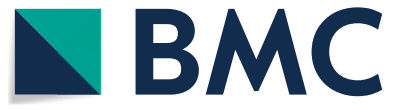

(c) The Author(s) 2021. Open Access This article is licensed under a Creative Commons Attribution 4.0 International License, which permits use, sharing, adaptation, distribution and reproduction in any medium or format, as long as you give appropriate credit to the original author(s) and the source, provide a link to the Creative Commons licence, and indicate if changes were made. The images or other third party material in this article are included in the article's Creative Commons licence, unless indicated otherwise in a credit line to the material. If material is not included in the article's Creative Commons licence and your intended use is not permitted by statutory regulation or exceeds the permitted use, you will need to obtain permission directly from the copyright holder. To view a copy of this licence, visit http://creativecommons.org/licenses/by/4.0/. The Creative Commons Public Domain Dedication waiver (http://creativecommons.org/publicdomain/zero/1.0/) applies to the data made available in this article, unless otherwise stated in a credit line to the data. 
the most common species (48\%) worldwide, followed by Rhinocladiella mackenziei (13\%) which was more common in the Middle East $[1,11,12]$.

Cladophialophora bantiana is a melanized, highly neurotropic fungus present in soil. It prefers a warmer climate with high humidity and has a wide geographic distribution (Asia, North and South America, Europe, and Africa) [11, 13, 14]. Cladophialophora bantiana virulence mechanisms are not clearly understood. A possible mechanism involves melanin production that interferes with microglial recognition, scavenging free radicals and hence preventing eradication of fungi from brain parenchyma $[15,16]$. In animal models, a common route of infection is through inhalation of airborne conidia [17], although lung infection with cerebral involvement is rarely documented [11]. Demographic data from reported cases demonstrate higher rates in men, residents from rural areas, and occupations such as farmers, agricultural workers, florists, gardeners, fruit workers and coal miners $[1,11,18-20]$. More than half of infections occur in patients with no known immunosuppression [1, 7]. Although other agents of cerebral phaeohyphomycosis have been described in patients with CARD9 deficiency, there are no reports to date of C. bantiana infections associated with this primary immunodeficiency [5]. Mutations in CARD9 affect innate immunity through alterations in signaling and recognition of the fungal cell wall [21].

Early diagnosis and treatment of dematiaceous molds can be challenging, with radiological features that mimic high grade gliomas, lymphomas, or tuberculomas [14, 22-25]. In one review of $C$. bantiana brain abscesses, diagnosis was delayed a mean 115 days from development of symptoms [19].

\section{Case presentation}

A 24-year-old man with no significant past medical history and on no medications presented to the emergency department with three weeks of headaches. One month prior to presentation he developed sinus pain, subjective fevers, nasal congestion, and ear fullness lasting for one week. He received an unknown course of antibiotics at the time. The symptoms improved; however, he noticed a new, constant headache with associated nausea, vomiting, blurry vision, and night sweats. He worked as a welder with prior employment in the coal industry. His hobbies included hunting and fishing and he reported significant time spent outdoors. Over the summer, he aerated his dirt basement after a plumbing leak.

On presentation, he was afebrile with normal vital signs and a non-focal physical exam. He had a white blood cell count of $10.4 \times 10^{3} / \mu \mathrm{L}$ (normal range 3.9-10.7 $\times 10^{3} /$ $\mu \mathrm{L}$ ) with $0 \%$ eosinophils and $80 \%$ neutrophils (absolute neutrophil count of $\left.8.37 \times 10^{3} / \mu \mathrm{L}\right)$. Erythrocyte sedimentation rate was $22 \mathrm{~mm} / \mathrm{h}$ (normal range $1-33 \mathrm{~mm} / \mathrm{h}$ ) and C-reactive protein was $3.1 \mathrm{mg} / \mathrm{L}$ (normal range $0-5 \mathrm{mg} / \mathrm{L}$ ). Computed tomography (CT) of the head was notable for three right parietotemporal masses with $9 \mathrm{~mm}$ midline shift and significant edema; sinus CT ruled out rhino-orbital involvement. He was started on dexamethasone with subsequent magnetic resonance imaging (MRI) confirming three irregular rim-enhancing lesions (Fig. 1A). He was taken to the operating room where he underwent stereotactic abscess evacuation with aspiration of purulent material. This was sent for bacterial, fungal and mycobacterial cultures and histopathological analysis. Microscopic examination of the abscesses revealed septate hyphal elements on the Gram stain (Fig. 1B).

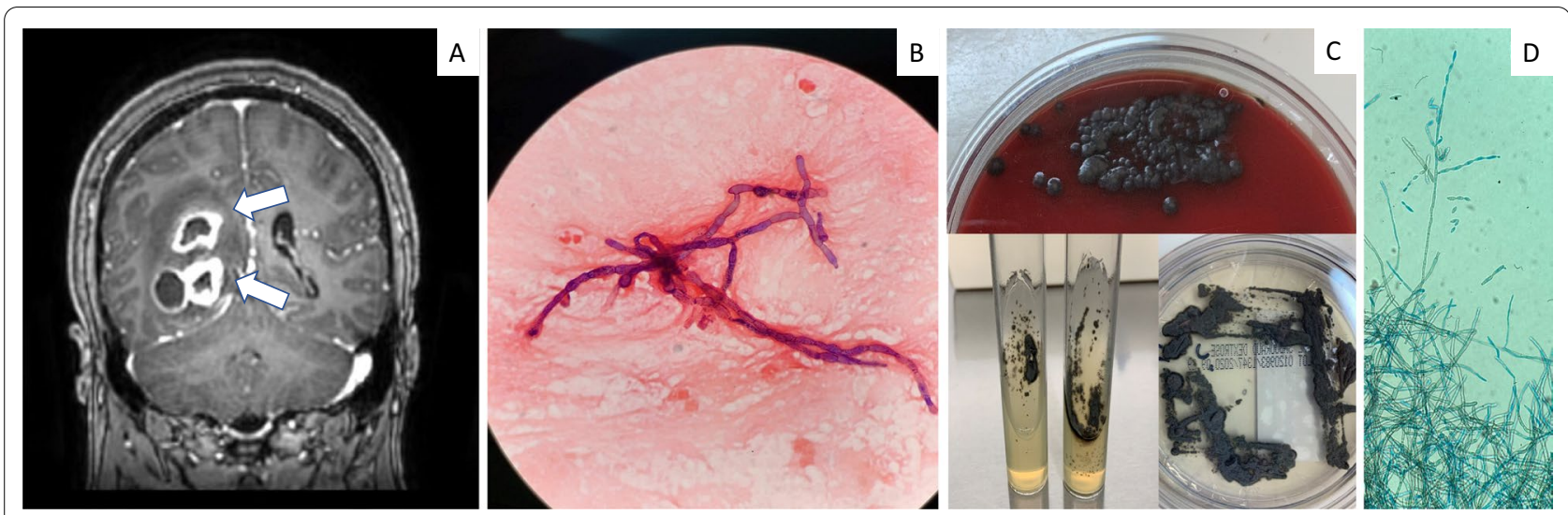

Fig. 1 A T1-weighted contrast-enhanced magnetic resonance image (MRI): coronal section through the posterior cranial fossa shows multiple rim-enhancing abscesses (arrows pointed) in the parieto-temporal lobes. B Gram-stain showing septate hyphae with sparse branching, under $\times$ 1000. C Olive-black velvety colonies of C. bantiana growing on Sheep Blood Agar, Sabouraud's Slant and Sabouraud's Plate. D Tape preparation of C. bantiana, stained with lactophenol cotton blue, showing melanized septate hyphal elements, under $\times 400$ 
Based on the gram stain result, he was started on liposomal amphotericin B, five milligrams per kilogram intravenously once daily. By day 6, fungal and bacterial cultures had grown a dematiaceous mold with velvety, olivaceous black colonies (Fig. 1C) at $30{ }^{\circ} \mathrm{C}$ and $35{ }^{\circ} \mathrm{C}$. Tape preparation of colonies with lactophenol cotton blue revealed long brown septate hyphae with sparsely branched wavy chains of smooth conidia (Fig. 1D). 5-Flucytosine $25 \mathrm{mg}$ per kilogram by mouth four times daily and posaconazole $300 \mathrm{mg}$ by mouth twice daily were added. Serum galactomannan antigen and $(1,3)-\beta-D-$ glucan serum tests returned negative, while baseline positron emission tomography (PET) CT showed known brain abscesses with a few small 5-6 $\mathrm{mm}$ lower lobe pulmonary nodules. Repeat MRI brain was obtained two weeks after the original surgery and demonstrated progression of abscesses and midline shift. He underwent operative debulking with resultant homonymous hemianopsia, but otherwise tolerated treatment well. He completed a 6-week course of liposomal amphotericin B and has remained on 5-flucytosine and posaconazole since discharge.

\section{Discussion and conclusions}

Cerebral biopsy with microbiological culture and histological analysis remains the gold standard for diagnosis of brain abscesses. Gram stain of this patient's parietal abscess allowed for visualization of septate hyphae with growth in media in 6 days. DNA sequencing and susceptibility results returned after 13 days of isolate submission to the reference laboratory, University of Texas Health Science Center at San Antonio. Sequencing targets included ITS, TUB and TEF, with susceptibility results tabulated in Table 1. It can be challenging to identify $C$. bantiana phenotypically if mycology is not routinely performed at the home institution. This may lead to further delays in diagnosis since the organism must be sent out for reference identification. Cladophialophora bantiana forms olivaceous black colonies with a velvety texture and can grow at higher temperatures $\left(42{ }^{\circ} \mathrm{C}\right)$. Microscopically, its short chaining septate hyphae and smooth conidia are similar to Cladosporium spp, however it lacks conidiophores [3, 26].

There is relatively little guidance on treatment of CNS phaeohyphomycosis in the literature [27]. In the few cases reported, surgical intervention with combination antifungal therapy is warranted [3, 19, 27]. The optimal duration of treatment is not clearly defined but antifungal therapy is typically given for several weeks to months or longer [28]. Despite aggressive intervention involving wide excision of infected parenchymal tissue, the mortality rate remains over $70 \%$, particularly in immunosuppressed patients. Furthermore, prognosis is worse in patients with multiple lesions $[1,16,19,20,29,30]$. Among available antifungal treatments for CNS phaeohyphomycosis, 5-flucytosine and voriconazole achieve a high cerebrospinal fluid concentration with their low molecular weight, low to intermediate lipophilicity, and lower protein binding [27, 31]. Liposomal amphotericin $\mathrm{B}$ and posaconazole provide less CNS penetration as relatively larger molecules, however they are often used as part of combination antifungal therapy [32-34]. Prolonged voriconazole use may be limited by its propensity to cause skin cancer, a known association in solid organ transplant recipients, and fluorosis [6, 27, 35]. Posaconazole may be an appropriate alternative for long-term maintenance and suppressive therapy with excellent in vitro activity [4].

Several barriers to treatment can limit favorable outcomes. For one, a scarcity of cases complicate efforts to compare treatments, with therapeutic recommendations based on in vitro data [36] and expert opinion only. Murine models suggest that residual mold may persist in brain tissue even after extended antifungal treatmentfor this reason, patients often require indefinite suppressive therapy [6, 27, 37]. Finally, long hospital stays are often necessary for invasive surgical debridement measures and administration of liposomal amphotericin B in a closely monitored setting.

Cladophialophora bantiana CNS infections are exceedingly uncommon in North America. Despite improved understanding of the disease and accessibility

Table 1 *Badali, H., et al., Use of amplified fragment length polymorphism to identify 42 Cladophialophora strains related to cerebral phaeohyphomycosis with in vitro antifungal susceptibility. J Clin Microbiol, 2010. 48(7): p. 2350-6

\begin{tabular}{llll}
\hline Antifungals & $\mathbf{m g} / \mathbf{L}$ & $\begin{array}{l}\text { In-vitrosusceptibility MIC range } \mathbf{( n = 3 7 ,} \\
\mathbf{m g} / \mathbf{L}) *\end{array}$ & Interpretation** \\
\hline Amphotericin B (AMB) & 4 & $0.12-2.0$ & No established breakpoints \\
5-Fluorocytosine (5-FC) & 0.25 & Not listed & No established breakpoints \\
Posaconazole (POS) & $<=0.03$ & $0.01-0.25$ & No established breakpoints \\
Voriconazole (VORI) & 0.125 & $0.12-4.0$ & No established breakpoints
\end{tabular}

${ }^{* *}$ Methodology: CLSI M38 
of therapeutic options, prognosis remains poor. Highlighting documented cases in the literature can increase awareness, with gradual progress towards earlier detection and standardized treatment. Nevertheless, the relationship between types of diagnostic methods and patient outcomes should be explored further. Gram stain as well as accurate and timely microbiological analysis provided direct benefit for our patient, but novel approaches like next-generation sequencing could play a complementary role in identification of disease and potentially reduce time from symptom onset to diagnosis in the future.

\section{Abbreviations \\ CT: Computed tomography; PET: Positron emission tomography; MRI: Magnetic resonance imaging; CNS: Central nervous system; DNA: Deoxyri- bonucleic acid; CARD9: Caspase recruitment domain-containing protein 9; ITS: Internal transcribed spacer; TUB: Tubby protein homolog; TEF: Thyrotroph embryonic factor.}

\section{Acknowledgements}

The authors would like to thank the medical, nursing and laboratory team involved in the care of this patient. The authors would like to thank the Fungal Pathogenesis Section, National Institute of Allergy and Infectious Diseases (NIAID) for their guidance on therapy. Finally, the authors would like to thank the University of Texas Health Science Center at San Antonio for providing confirmatory identification and susceptibility testing.

\section{Authors' contributions}

PW and PM drafted the manuscript. PW, KB, KW, ML, RH and AM were the clinical team involved in the management of the case. TS and JS contributed to the initial identification of the mold. $\mathrm{RH}$ and $\mathrm{KB}$ provided critical edits to the manuscript. All authors were involved in reviewing and approving the final manuscript.

\section{Funding}

No funding was sought for this case report.

\section{Availability of data and materials}

All data generated or analyzed during this study are included in this manuscript.

\section{Declarations}

\section{Ethics approval and consent to participate} Not applicable.

\section{Consent for publication}

Written informed consent was obtained from the patient for publication of this case report and the accompanying images. Copy of the consent form is available for review by the editors of this journal.

\section{Competing interests}

The authors declare that they have no competing interests.

\section{Author details}

'Department of Pathology, Immunology and Microbiology, Vanderbilt University Medical Center, 1301 Medical Center Dr., TVC 4524, Nashville, TN 37232 USA. ${ }^{2}$ Department of Medicine, Division of Infectious Diseases, Vanderbilt University Medical Center, Nashville, TN, USA. ${ }^{3}$ Fungal Pathogenesis Section, Laboratory of Clinical Immunology and Microbiology, National Institute of Allergy and Infectious Diseases, Annapolis, MD, USA. ${ }^{4}$ Division of Intramural Research, National Institute of Allergy and Infectious Diseases, Annapolis, MD, USA.
Received: 26 August 2021 Accepted: 22 December 2021

Published online: 04 January 2022

\section{References}

1. Revankar SG, Sutton DA, Rinaldi MG. Primary central nervous system phaeohyphomycosis: a review of 101 cases. Clin Infect Dis. 2004;38(2):206-16.

2. Thomas E, et al. From phaeohyphomycosis to disseminated chromoblastomycosis: a retrospective study of infections caused by dematiaceous fungi. Med Mal Infect. 2018;48(4):278-85.

3. Revankar SG, Sutton DA. Melanized fungi in human disease. Clin Microbiol Rev. 2010;23(4):884-928.

4. Velasco J, Revankar S. CNS infections caused by brown-black fungi. J Fungi (Basel). 2019;5(3):60.

5. Vaezi A, et al. Frequency and geographic distribution of CARD9 mutations in patients with severe fungal infections. Front Microbiol. 2018;9:2434.

6. Arcobello JT, Revankar SG. Phaeohyphomycosis. Semin Respir Crit Care Med. 2020;41(1):131-40.

7. Bonifaz A, et al. Severe disseminated phaeohyphomycosis in an immunocompetent patient caused by Veronaea botryosa. Mycopathologia. 2013;175(5-6):497-503.

8. Badali $\mathrm{H}$, et al. First autochthonous case of Rhinocladiella mackenziei cerebral abscess outside the Middle East. J Clin Microbiol. 2010;48(2):646-9.

9. Badali H, et al. Cladophialophora saturnica sp. nov., a new opportunistic species of Chaetothyriales revealed using molecular data. Med Mycol. 2009:47(1):51-62.

10. Badali $\mathrm{H}$, et al. Cladophialophora psammophila, a novel species of Chaetothyriales with a potential use in the bioremediation of volatile aromatic hydrocarbons. Fungal Biol. 2011;115(10):1019-29.

11. Kantarcioglu AS, et al. An updated comprehensive systematic review of Cladophialophora bantiana and analysis of epidemiology, clinical characteristics, and outcome of cerebral cases. Med Mycol. 2017;55(6):579-604.

12. Mohammadi R, et al. Cerebral phaeohyphomycosis due to Rhinocladiella mackenziei in Persian Gulf region: a case and review. Mycoses. 2018;61(4):261-5.

13. Garg N, et al. Central nervous system cladosporiosis: an account of ten culture-proven cases. Neurol India. 2007;55(3):282-8.

14. Khaliq MF, Ihle RE, Schirtzinger CP. Cladophialophora bantiana cerebral phaeohyphomycosis complicated by pulmonary nocardiosis: a tale of two infections. Case Rep Infect Dis. 2019;2019:4352040.

15. Koutsouras GW, Ramos RL, Martinez LR. Role of microglia in fungal infections of the central nervous system. Virulence. 2017;8(6):705-18.

16. Kantarcioglu AS, de Hoog GS. Infections of the central nervous system by melanized fungi: a review of cases presented between 1999 and 2004. Mycoses. 2004;47(1-2):4-13.

17. Dixon DM, et al. Experimental central nervous system phaeohyphomycosis following intranasal inoculation of Xylohypha bantiana in cortisonetreated mice. Mycopathologia. 1987;100(3):145-53.

18. Goralska K, Blaszkowska J, Dzikowiec M. Neuroinfections caused by fungi. Infection. 2018;46(4):443-59.

19. Chakrabarti A, et al. Brain abscess due to Cladophialophora bantiana: a review of 124 cases. Med Mycol. 2016;54(2):111-9.

20. Suri P, et al. Cerebral phaeohyphomycosis due to Cladophialophora bantiana - a case report and review of literature from India. J Clin Diagn Res. 2014;8(4):DD01-5.

21. Drummond RA, et al. CARD9-dependent neutrophil recruitment protects against fungal invasion of the central nervous system. PLoS Pathog. 2015;11(12):e1005293.

22. Kantarcioglu AS, et al. A case of central nervous system infection due to Cladophialophora bantiana. Rev Iberoam Micol. 2016;33(4):237-41.

23. Sood P, et al. Brain abscess due to Xylohypha bantiana. Scand I Infect Dis. 2000;32(6):708-9.

24. Rossmann SN, Cernoch PL, Davis JR. Dematiaceous fungi are an increasing cause of human disease. Clin Infect Dis. 1996;22(1):73-80.

25. Agrawal A, et al. Cladophialophora bantiana brain abscess masquerading cerebral tuberculoma in an immunocompetent host. Roman Neurosurg. 2014;21(1):73-7. 
26. Larone $\mathrm{DH}$. Medically important fungi: a guide to identification. 6th ed. Washington: American Society for Microbiology ASM; 2018.

27. Chowdhary A, et al. ESCMID and ECMM joint clinical guidelines for the diagnosis and management of systemic phaeohyphomycosis: diseases caused by black fungi. Clin Microbiol Infect. 2014;20(Suppl 3):47-75.

28. Revankar SG. Therapy of infections caused by dematiaceous fungi. Expert Rev Anti Infect Ther. 2005;3(4):601-12.

29. Jung NY, Kim E. Cerebral phaeohyphomycosis: a rare cause of brain abscess. J Korean Neurosurg Soc. 2014;56(5):444-7.

30. Gongidi P, et al. Cerebral phaeohyphomycosis in a patient with neurosarcoidosis on chronic steroid therapy secondary to recreational marijuana usage. Case Rep Radiol. 2013;2013:191375.

31. Felton T, Troke PF, Hope WW. Tissue penetration of antifungal agents. Clin Microbiol Rev. 2014;27(1):68-88.

32. Miceli MH. Central nervous system infections due to aspergillus and other hyaline molds. J Fungi (Basel). 2019;5(3):79.

33. Schwartz S, Thiel E. Cerebral aspergillosis: tissue penetration is the key. Med Mycol. 2009;47(Suppl 1):S387-93.

34. Lee $\mathrm{A}$, et al. Tissue distribution and penetration of isavuconazole at the site of infection in experimental invasive Aspergillosis in mice with underlying chronic granulomatous disease. Antimicrob Agents Chemother. 2019;63(6):e00524-e619.

35. D'Arcy ME, et al. Voriconazole and the risk of keratinocyte carcinomas among lung transplant recipients in the United States. JAMA Dermatol. 2020;156(7):772-9.

36. Badali $\mathrm{H}$, et al. Use of amplified fragment length polymorphism to identify 42 Cladophialophora strains related to cerebral phaeohyphomycosis with in vitro antifungal susceptibility. J Clin Microbiol. 2010;48(7):2350-6.

37. Al-Abdely HM, et al. Antifungal therapy of experimental cerebral phaeohyphomycosis due to Cladophialophora bantiana. Antimicrob Agents Chemother. 2005;49(5):1701-7.

\section{Publisher's Note}

Springer Nature remains neutral with regard to jurisdictional claims in published maps and institutional affiliations.

Ready to submit your research? Choose BMC and benefit from:

- fast, convenient online submission

- thorough peer review by experienced researchers in your field

- rapid publication on acceptance

- support for research data, including large and complex data types

- gold Open Access which fosters wider collaboration and increased citations

- maximum visibility for your research: over $100 \mathrm{M}$ website views per year

At BMC, research is always in progress.

Learn more biomedcentral.com/submissions 